\title{
Alcohol Use among Medical Students: Linking Knowledge as a Social Capital Defining Norms in Learning Institutions
}

\author{
Patrick N. Njagi and Ronnie Midigo
}

\section{ABSTRACT}

College alcohol use continues to be a national public health issue. World Health Organization approximates that $53 \%$ of people at the age of 15 years and above, have at one time used alcohol. Alcohol is recognized and acts as 'entrance' to the use of other substances. The study was carried out in Kenya Medical Training College, Embu Campus. The study presents an argument that knowledge about alcohol is a social capital defining use and non-use of alcohol among medical students at Kenya Medical Training College. A Cross-sectional analytical approach was adopted for the study design. A sample of 270 students was included in the study. Data was analyzed using both descriptive (Frequencies and percentages) and inferential statistics (chi square tests and regression analysis). For objective one, the study finds a 75\% prevalence rate of alcohol use among students of Embu MTC. Demographic factors influencing alcohol use include, religion $(p=0.002205)$, program undertaken $(\mathbf{p}<0.0001)$ and with whom the respondent is living with $(p<0.0001)$. The study recommends development and implementation of policies and programs aimed at addressing the widespread use of alcohol in the study site.

Submitted : November 10, 2020

Published : February 23, 2021

ISSN: 2593-8339

DOI: 10.24018 /ejmed.2021.3.1.504

Patrick N. Njagi*

Kenya Medical Training College, Kenya.

(e-mail: njue60.pn@gmail.com)

Ronnie Midigo

University of Nairobi, Kenya.

(e-mail: ronniemidigo@gmail.com)

*Corresponding Author

Keywords: Alcohol, Students, non-communicable disease, Knowledge, prevalence.

\section{INTRODUCTION}

Usage of alcohol is increasingly being reported across the globe [1]. Studies have linked alcohol use with upsurge of associated non communicable diseases [2], [3]. In Kenya, reports of lives being destroyed by alcohol addiction have increased with students in colleges reported as most susceptible to excessive use of alcohol [4]. The problem has increased in learning institutions leading to increase in idleness and drop outs both at high school and tertiary learning institutions. It is estimated that about $51.9 \%$ of college students reported lifetime use of alcohol in colleges and universities [5].

Studies shows that many grown-ups who engage in excess alcohol drinking behavior began using alcohol when they were less than 21 years old [6], [7]. According to Carvalho, Heilig [1], continued alcohol use regularly takes control of the user who in the end become addicted. With this background therefore, it can be reasoned that that continued use of alcohol among students implies upsurge of associated NCDs among the youthful population. Medical students are trained to take up roles in promoting health, and more primary healthcare promotion. Their use of alcohol given the associated NCDs would therefore conflict with the mission of their training.

Research associated to substance abuse and alcohol usage among Kenyan students has been done by many scholars. For Instance, Atwoli, Mungla [2] conducted a study on
Prevalence of substance use among college students in Kenya and found out that socio-demographic factors was significantly associated with this. Odonde [3] conducted a similar study and found out that among the factors influencing use of alcohol include students' background, residence, family genetics and drug abuse in high school.

The concept of social capital has been discussed by many theorists [10]-[12]. In the discourse on knowledge management, the concept of social capital plays a key role as the mediator of individual know-how or 'human capital' which can be used to navigate through challenges in the society [12]. There are various forms of capital as alluded to by Bourdieu (4) include cultural, economic, administrative capital, physical capital, political capital, social capital and symbolic capital. Social capital is defined by Bourdieu [5] as subjective phenomenon formed by values and attitudes which influence interactions. As such, social capital should be considered in terms of three clusters: structural, relational, and cognitive. This paper build on knowledge a social capital that medical students can utilize to enable them to navigate through the attractions towards use of alcohol.

\section{METHODS}

This was a cross-sectional analytical study utilizing both quantitative and qualitative data collection methods. It was conducted in Kenya medical training college Embu. The study population comprised both resident and non-resident 
students enrolled in Embu KMTC at the time of the study. Sample size was determined by use of the Fisher et al. [6] where a total of 277 respondents were sampled. Structured questionnaires were used to collect quantitative data from the students. Qualitative data was collected through Focus Group Discussion. All qualitative and quantitative data collected were analyzed using computer assisted software. Thematic analysis was employed in analyzing the qualitative data. As such, emerging themes were identified and coded. This was assisted by computer qualitative data analysis software (MAXQDA). Quantitative data entered in the SPSS software were analyzed using both descriptive and inferential statistics.

\section{RESULTS}

\section{A. Demographic Characteristic of Study Population}

Demographic factors investigated included gender, age, marital status, religion, year of study and program undertaken. Table 1 below contains the demographic characteristics of the respondents.

From Table, $53.3 \%$ of the respondents were male while $46.7 \%$ were female. About $81.3 \%$ of the respondents were aged between 19-24 years. On marital status, the study findings reveal that $84 \%$ of the respondents were single while $14.7 \%$ were married. About $86.3 \%$ were of the Christian religion, and $11.3 \%$, Muslims. The study also revealed that $39.3 \%$ were 3 rd year students, $33.3 \%$, 2nd year students and $26.7 \%, 1$ st year students. Also, $42 \%$ of the respondents were enrolled in nursing programs, 38\%, Clinical Medicine, $11.3 \%$, medical laboratory Sciences program while $8.3 \%$ were enrolled in Environmental Health Sciences

TABLE 1: DEMOGRAPHIC CHARACTERISTICS OF THE RESPONDENTS

\begin{tabular}{llcc}
\hline & & $F$ & $p$ \\
\hline \multirow{2}{*}{ Gender } & Male & 160 & 53.3 \\
Age & Female & 140 & 46.7 \\
& 16 - 18 years & 11 & 3.7 \\
\multirow{4}{*}{ Marital status } & 19-24 years & 244 & 81.3 \\
& Over 24 years & 45 & 15 \\
& Married & 44 & 14.7 \\
Religion & Single & 252 & 84 \\
& Divorced & 2 & 0.7 \\
& Christian & 259 & 86.3 \\
Year of study & Muslim & 34 & 11.3 \\
& Others & 6 & 2 \\
& 1st year & 80 & 26.7 \\
& 2nd year & 100 & 33.3 \\
& 3rd year & 118 & 39.3 \\
& 4th year & 1 & 0.3 \\
Program being & Clinical Medicine & 114 & 38 \\
undertaken & Nursing & 126 & 42 \\
& Environmental & 25 & 8.3 \\
& Health Sciences & & \\
& Medical & 34 & 11.3 \\
& Laboratory & &
\end{tabular}

\section{B. Prevalence of Alcohol Use}

To investigate prevalence of alcohol use, respondents were asked to indicate whether they ever consumed alcohol. This was compared across the various demographic factors. Fig. 1 below presents the findings.

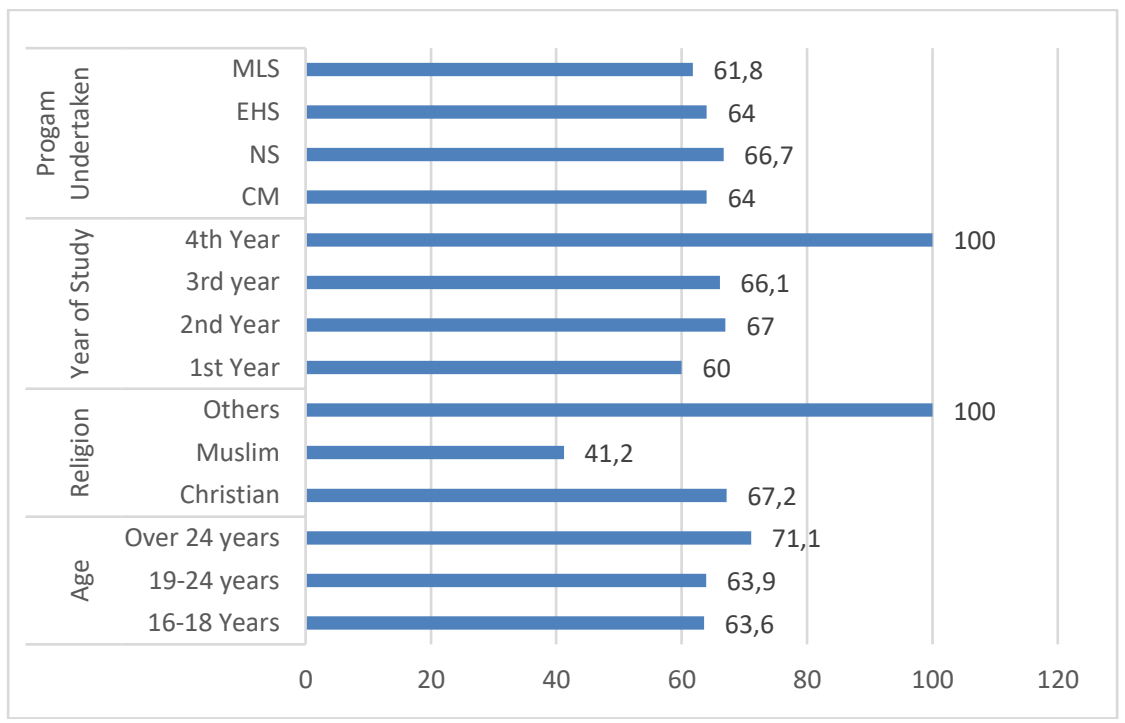

Fig. 1. Prevalence of Alcohol Use among Different Demographic Cohorts.

Overall, about $75 \%$ of the respondents indicated that they used alcoholic drinks. About $71.1 \%$ of those aged 24 years and above indicated that they used alcoholic drinks. The findings also reveal that $67.2 \%$ of those who professed Christian religion, $41.2 \%$ and all (100\%) of those who were neither Muslims nor Christians indicated that they used alcoholic drinks. All (100\%) of the sampled students who were in their 4th year indicated that they used alcoholic drinks. Those who were in their 1st year, $60 \%$, 2nd year $67 \%$ and 3rd year, $66.1 \%$ indicated that they used alcoholic drinks. Also, $66.7 \%$ of students enrolled in nursing program, $64 \%$ of those enrolled in clinical medicine programs, and
Environmental Health program and $61.8 \%$ of those enrolled in medical laboratory science programs indicated that they used alcoholic drinks.

During a Focus group Discussion, it emerged that alcohol use among students was perceived to be very high. This was attributed to the local culture of alcohol consumption since most of the students enrolled in the institution interacted freely with the local community. One participant indicated that:

Many students, I can't say what percentage, take alcohol. Some of them you may not know.... but 
when they get opportunity, they take alcohol (FGD, Female)

\section{Influence of Knowledge about Alcohol on Its Use}

To establish the influence of knowledge about alcohol on its use among students, a modified Student Alcohol Questionnaire was used. The questionnaire contained a total of eight questions and scores were made as provided by the tool. Table 2 below presents the scores from the SAQ.

\begin{tabular}{lcc}
\multicolumn{3}{c}{ TABLE 2: SAQ ALCOHOL KNOWLEDGE } \\
\hline \multicolumn{1}{c}{ SAQ } & CORRECT & FALSE \\
\hline $\begin{array}{l}\text { Alcohol is a valuable food } \\
\text { It is not dangerous to drive when you have } \\
\text { been drinking alcohol }\end{array}$ & 59 & 41 \\
$\begin{array}{l}\text { You can drink yourself to death if you take } \\
\text { too much alcohol too quickly }\end{array}$ & 58 & 54 \\
$\begin{array}{l}\text { The body can handle the amount of } \\
\text { alcohol in an 8 oz. } \\
\text { glass of beer every hour Alcohol is a } \\
\text { chemical stimulant }\end{array}$ & 46 & 52 \\
$\begin{array}{l}\text { People can become physically dependent } \\
\text { on alcohol }\end{array}$ & 46 & 54 \\
$\begin{array}{l}\text { People usually become very hungry when } \\
\text { they drink a lot of alcohol }\end{array}$ & 76 & 24 \\
$\begin{array}{l}\text { The caffeine in a couple of cups of strong } \\
\text { coffee will help sober a person up }\end{array}$ & 74 & 26 \\
\hline
\end{tabular}

The findings in Table 2 indicate that most of the respondents had good knowledge about alcohol. The scores were then averaged to come up with the individual scores for all the sampled respondents. This was as presented in Fig. 2 below.

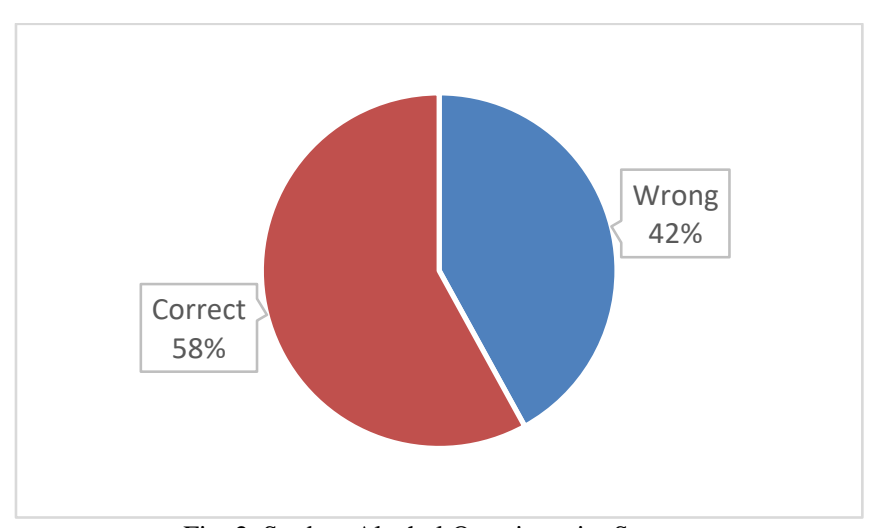

Fig. 2. Student Alcohol Questionnaire Scores.

Out of 8 possible answers, the total group obtained a mean score of 4.46 which represented $58 \%$, or a little over one half, of the questions being answered correctly. Chi squared test revealed a significant association between use of alcohol and the knowledge score. Table 3 below presents the findings.

\begin{tabular}{|c|c|c|c|c|c|}
\hline \multirow{2}{*}{ AUQ } & & \multicolumn{2}{|c|}{ Uses alcoholic drink } & \multirow{2}{*}{ CL $(95 \%)$} & \multirow{2}{*}{$\mathrm{P}$-value } \\
\hline & & Yes & No & & \\
\hline \multirow{2}{*}{ Alcohol is a valuable food } & Correct & $78(44.1)$ & $99(55.9)$ & 1 & \multirow{2}{*}{$<0.00001$} \\
\hline & False & $119(96.7)$ & $4(3.3)$ & $0.0(0.01-0.07)$ & \\
\hline \multirow{2}{*}{$\begin{array}{c}\text { It is not dangerous to drive when you have been } \\
\text { drinking alcohol }\end{array}$} & Correct & $57(41.3)$ & $81(58.7)$ & 1 & \multirow{2}{*}{$<0.00001$} \\
\hline & False & $140(86.4)$ & $22(13.6)$ & $0.1(0.06-0.19)$ & \\
\hline \multirow{2}{*}{$\begin{array}{l}\text { You can drink yourself to death if you take too } \\
\text { much alcohol too quickly }\end{array}$} & Correct & $79(45.4)$ & $95(54.6)$ & 1 & \multirow{2}{*}{$<0.00001$} \\
\hline & False & $118(93.7)$ & $8(6.3)$ & $0.1(0.03-0.12)$ & \\
\hline \multirow{2}{*}{$\begin{array}{l}\text { The body can handle the amount of alcohol in an } 8 \\
\text { oz. }\end{array}$} & Correct & $52(37.7)$ & $86(62.3)$ & 1 & \multirow{2}{*}{$<0.00001$} \\
\hline & False & $145(89.5)$ & $17(10.5)$ & $0.1(0.04-0.13)$ & \\
\hline \multirow{2}{*}{$\begin{array}{c}\text { glass of beer every hour Alcohol is a chemical } \\
\text { stimulant }\end{array}$} & Correct & $55(39.9)$ & $83(60.1)$ & 1 & \multirow{2}{*}{$<0.00001$} \\
\hline & False & $142(87.7)$ & $20(12.3)$ & $0.1(0.05-0.17)$ & \\
\hline \multirow{2}{*}{$\begin{array}{l}\text { People can become physically dependent on } \\
\text { alcohol }\end{array}$} & Correct & $143(62.7)$ & $85(37.3)$ & 1 & \multirow{2}{*}{0.0557} \\
\hline & False & $54(75.0)$ & $18(25.0)$ & $0.6(0.31-1.02)$ & \\
\hline \multirow{2}{*}{$\begin{array}{l}\text { People usually become very hungry when they } \\
\text { drink a lot of alcohol }\end{array}$} & Correct & $143(64.4)$ & $85(38.3)$ & 1 & \multirow{2}{*}{0.0557} \\
\hline & False & $54(69.2)$ & $18(23.1)$ & $0.6(0.31-1.02)$ & \\
\hline \multirow{2}{*}{$\begin{array}{l}\text { The caffeine in a couple of cups of strong coffee } \\
\text { will help sober a person up }\end{array}$} & Correct & $79(45.4)$ & $95(54.6)$ & 1 & \multirow{2}{*}{$<0.00001$} \\
\hline & False & $118(93.7)$ & $8(6.3)$ & $0.1(0.03-0.12)$ & \\
\hline
\end{tabular}

The study found a strong relationship between knowledge variable and use of alcohol save for the item on physical dependence on alcohol and hunger $(p>0.05)$. Most of the respondents with correct knowledge about alcohol did not use alcohol. On the other hand, respondents with incorrect knowledge about alcohol had lower odds of not using alcohol $(\mathrm{OR}<1)$. Regressions analysis on the influence of knowledge on alcohol use revealed significant $\mathrm{F}=0.025505$ and $\mathrm{t}=3.412394$. Table 4 below presents the regression analysis.

\begin{tabular}{|c|c|c|c|c|}
\hline \multicolumn{2}{|c|}{ Regression Statistics } & \multirow[t]{2}{*}{$\mathrm{F}$} & \multirow[t]{2}{*}{ t Stat } & $\begin{array}{c}\text { Significance } \\
\text { F }\end{array}$ \\
\hline Multiple R & 0.555436 & & & \\
\hline R Square & 0.308509 & & & \\
\hline $\begin{array}{l}\text { Adjusted R } \\
\text { Square }\end{array}$ & 0.259117 & 6.246112 & 3.412394 & 0.025505 \\
\hline $\begin{array}{l}\text { Standard } \\
\text { Error }\end{array}$ & 36.62773 & & & \\
\hline Observations & 16 & & & \\
\hline
\end{tabular}

\section{DISCUSSION}

\section{A. Prevalence of Alcohol Use}

The study established that the prevalence of alcohol use among students in Embu KMTC was 75\%. This finding indicates that out of 10 students enrolled in Embu KMTC, 8 are alcohol users. Within the demographics, prevalence rate of $67.2 \%$ was recorded among Christians, $41.2 \%$ among Muslims and $100 \%$ among individuals who were neither Muslims nor Christians. Prevalence of alcohol use within the levels of study was established to be $100 \%$ for 4 th year students, $60 \%$ for 1 st years, $67 \%$ for 2 nd years and $66.1 \%$ for 3rd years. Highest prevalence was recorded among students enrolled in nursing programs. The prevalence was also high among older students. These findings lead to an understanding that there is high prevalence of alcohol use in Embu KMTC and that higher prevalence was found among students professing Christian religion, older students, students enrolled in nursing programs and students in their 
second and fourth years of study.

The study finds very high prevalence of alcohol use among students in the study area. It is possible to reason that the prevalence rate of alcohol use in the study area is an exuberated reflection of the alcohol prevalence rates in Embu county given that it was comprised of students only. Peacock, Hall [7] established that globally, university students have a higher prevalence of alcohol abuse. Also, Dantzer, Wardle [8] indicated that in USA $40 \%$ of adolescents' abuse drugs and $60 \%$ abuse alcohol while in Asia $48.9 \%$ of University students' abuse alcohol, $24 \%$ being 1 st years while $75.6 \%$ are final years and that Ireland had higher proportions of male and female who abused alcohol.

\section{B. Influence of Knowledge about Alcohol on Alcohol Use}

The study established that over $50 \%$ of the students sampled had above average knowledge about alcohol. Knowledge about alcohol was found to influence alcohol use. Students who had above average knowledge about alcohol did not use alcohol. Poor knowledge about alcohol could be as a result of misconceptions and misunderstanding about the actual component of alcohol.

This finding leads to an understanding that use of alcohol in the institution could be due to lack of sufficient knowledge on alcohol. According to Bernhardt, Nebe [9], many alcohol users hold to misconceptions and advertisement ideas propagated in the society and thus are lacking proper knowledge about alcohol. The scholars postulate that if proper knowledge was provided, most people using alcohol would quit alcohol use. Further, a study by Valentine, Schumacher [10] on university students' lifestyles revealed a need for better education about alcohol, drugs, and general health in universities. It is on this finding that an argument is advance for social capital as defined by reference [12] to include knowledge as a capital necessary for successful navigation in the challenges of life

\section{CONCLUSIONS AND RECOMMENDATIONS}

The study concludes that there is high prevalence of alcohol use among students of Embu MTC. The study also concludes that alcohol use among students at Embu MTC is influenced by their knowledge on alcohol. This knowledge defines their social capital and thus students with good knowledge about alcohol were less likely to use alcohol.

Based on the established high prevalence rates of alcohol use in the study area, the study recommends development of alcohol use policy specific to the institution with an aim of regulating and controlling alcohol use among students registered in the institution. Since the study finds a relationship between knowledge about alcohol and its use among the students, the study recommends awareness drives aimed at increasing knowledge about alcohol and its correlates among the student population.

\section{ACKNOWLEDGMENT}

We acknowledge the support given to us by Dr. Isaac Okeyo of Technical University of Kenya and Dr. Blsio Omuga of the University of Nairobi. We also acknowledge the support from our peers, Danny Mungai and Faith Githongo with whom we undertook academic engagement. Also acknowledged are the respondents drawn from the Kenya Medical Training College.

\section{REFERENCES}

[1] Carvalho AF, Heilig M, Perez A, Probst C, Rehm J. Alcohol use disorders. The Lancet. 2019;394(10200):781-92.

[2] Atwoli L, Mungla PA, Ndung'u MN, Kinoti KC, Ogot EM. Prevalence of substance use among college students in Eldoret, western Kenya. BMC psychiatry. 2011;11(1):1-9.

[3] Odonde PA. Factors influencing drugs and substance abuse among students at Ramogi Institute of Advanced Technology-Kenya: University of Nairobi, Kenya; 2010.

[4] Bourdieu P. The forms of capital.(1986). Cultural theory: An anthology. 2011;1:81-93.

[5] Bourdieu P. Outline of a Theory of Practice. Cambridge, MA. Cambridge Univ. Press; 1972.

[6] Fisher A, JohnE.taing, JohnE.Stoeckel, JohnW.Townsend. Handbook for Family PlanningOperations ResearchDesign. Second ed. New York: Population Council; 1991.

[7] Peacock A, Hall W, Degenhardt L. Epidemiology of Substance Use Internationally. Prevention of Substance Use: Springer; 2019. p. 1936.

[8] Dantzer C, Wardle J, Fuller R, Pampalone SZ, Steptoe A. International study of heavy drinking: Attitudes and sociodemographic factors in university students. Journal of American College Health. 2006;55(2):83-90.

[9] Bernhardt N, Nebe S, Pooseh S, et al. Impulsive Decision Making in Young Adult Social Drinkers and Detoxified Alcohol-Dependent Patients: A Cross-Sectional and Longitudinal Study. Alcoholism: clinical and experimental research. 2017;41(10):1794-807.

[10] Valentine AA, Schumacher JR, Murphy J, Ma YJ. Dietary supplement use, perceptions, and associated lifestyle behaviors in undergraduate college students, student-athletes, and ROTC cadets. Journal of American College Health. 2018;66(2):87-97.

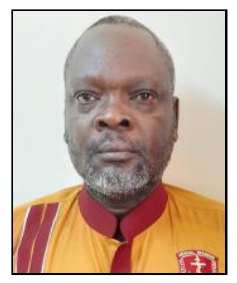

Patrick Njagi has training background in clinical medicine and surgery. He holds A Msc in Public Health. Currently teaching at Kenya Medical Training College, Department of Clinical Medicine and also serving as the current Deputy Principal of the College in Embu Campus. 